\title{
Genetic connectivity patterns of Pocillopora verrucosa in southern African Marine Protected Areas
}

\author{
Tyrone Ridgway ${ }^{1, *}$, Cynthia Riginos ${ }^{2}$, Jasmine Davis ${ }^{1}$, Ove Hoegh-Guldberg ${ }^{1}$
}

${ }^{1}$ Centre for Marine Studies, and ${ }^{2}$ School of Integrative Biology, University of Queensland, St Lucia, Queensland 4072, Australia

\begin{abstract}
A coherent management plan for coral reef communities should take into account the patterns of connections among distant reefs in order to prioritise conservation efforts to those areas that are important larval sources. At present, the inclusion of such connectivity assessments into Marine Protected Area (MPA) planning is hindered by the lack of knowledge of the exact patterns of connectivity among reefs. To evaluate such patterns, microsatellite loci were used to assess the population genetic structure of the coral Pocillopora verrucosa in currently established MPAs in South Africa and southern Mozambique. All local collections were sexually reproducing (mean genotypic diversity ratio $N_{\mathrm{g}}: N=0.88$ ) and differed significantly from Hardy-Weinberg equilibrium due to heterozygote deficits, and genetic diversity decreased with increasing latitude. Bayesian analyses (using STRUCTURE) and $F_{\mathrm{ST}}$ analysis $\left(F_{\mathrm{ST}}=0.054\right)$ identified southern Mozambique as a separate cluster from South Africa, suggesting weak connectivity between southern Mozambique and South African reef communities over ecological time scales. However, southern Mozambican reefs may contribute recruits to the South African reefs over many generations via a stepping-stone approach, highlighting that the conservation of reefs operates on scales that are often beyond geographical/political boundaries.
\end{abstract}

KEY WORDS: Coral $\cdot$ Microsatellites $\cdot$ Connectivity $\cdot$ MPAs $\cdot$ Southern Africa

Resale or republication not permitted without written consent of the publisher

\section{INTRODUCTION}

Despite the apparent benefits of maintaining healthy reef systems, coral reefs in the Indian Ocean are becoming degraded at an alarming rate. During the 1998 mass bleaching event, more than $90 \%$ of shallow corals were killed on most Indian Ocean reefs (Sheppard 2003), which was of major concern given the important role that reefs play in providing resources (fisheries, building materials, supporting tourism) to local communities. Besides bleaching, the main contributors to the rapid decline of Indian Ocean coral reefs are degradation from land-based pollution, overexploitation, destructive fishing techniques, and human-induced erosion (Berg et al. 2002). Although reefs are obviously declining, the level of protection in the Indian Ocean is well below Roughgarden \& Armsworth's (2001) recommendation that at least 30\% of an ecosystem should be protected from resource exploitation for long-term sustainability to be possible. Kenya, Mozambique, Somalia, South Africa, Tanzania, Comoros, Madagascar, Mauritius, Reunion, and the Seychelles encompass the Western Indian Ocean (approximately 24 million $\mathrm{km}^{2}$ ) with 54 established Marine Protected Areas (MPAs). However, only $2000 \mathrm{~km}^{2}$ are actually protected (about $1 \%$ ), and of these, McClanahan (1999) argued that only 8 MPAs (total area of $40 \mathrm{~km}^{2}$ ) effectively restrict resource extraction.

The size and shape of areas for protection ideally should depend on the connectivity among diverse habitats used by different species and life stages. A coherent management plan for coral reef communities therefore needs to take into account the patterns of connections among distant reefs in order to prioritise conservation efforts to those areas that are important 
larval sources (Palumbi 2003). Scleractinian corals are the major framework builders of coral reefs providing the reef matrix, which in turn sustains the most biologically diverse ecosystem in the ocean. Scleractinian corals are therefore important candidates for connectivity assessments, and allozyme electrophoresis has shown that populations of some brooding and broadcasting corals are at least partially maintained by localised settlement of larvae, yet there are sufficient widely dispersed larvae to maintain high levels of gene flow (Ayre \& Hughes 2000). Furthermore, high latitude reefs appear to be genetically depauperate, and levels of gene flow among corals separated by a few hundred kilometres of open water are generally low (e.g. Ayre \& Hughes 2004).

The inclusion of connectivity assessments into MPA planning is currently hindered by the lack of knowledge of the exact patterns of connectivity among reefs (Mora \& Sale 2002). For the Western Indian Ocean, Ridgway \& Sampayo (2005) recently reviewed the level of genetic knowledge in the region and revealed that the Western Indian Ocean shows little apparent genetic exchange with the rest of the Indo-Pacific, but from a regional perspective there was very limited information available. Only 27 potentially relevant references were found, with only one purely Western Indian Ocean regional population genetic study on a single coral species on a restricted scale (Ridgway et al. 2001). Ridgway et al. (2001) used allozymes on Pocillopora verrucosa, a simultaneous hermaphroditic broadcast spawner, and widespread larval dispersal was therefore expected. Indeed, the allozyme variation of populations from 6 reef locations within the Central and Southern Reef Complexes in South Africa implied that both reef complexes support a single, genetically homogenous population. Within reefs, genetic variation was maintained by high levels of localised sexual recruitment together with sufficiently high levels of long distance larval dispersal to prevent the development of any significant geographic differentiation. However, the inclusion of collections from farther north of these sampled populations and the use of more sensitive DNA markers is necessary to enhance the management potential of the data on coral connectivity patterns in southern Africa.

In the present study we expanded on the results of Ridgway et al. (2001) by including collections from northern South Africa and southern Mozambique. Despite using few loci, microsatellites on corals in general have shown significant population structuring on large spatial scales, but limited differentiation on local scales (Baums et al. 2005, Magalon et al. 2005). We used newly isolated Pocillopora microsatellite markers (Magalon et al. 2004) to test whether Mozambican and South African populations of Pocillopora verrucosa constitute a single connected unit, in order to provide an initial evaluation of connectivity among currently established MPAs in southern Africa. This is important given the significant investment in reef protection in South Africa, in direct contrast to the very limited protection in its upstream neighbour, Mozambique. Marine populations are not necessarily restricted to geographic borders; thus, this baseline study is timely because it addresses the importance of connectivity assessments for coral reef management, which is particularly acute given the low level of coral reef protection and the disparity in levels of protection among countries in the Indian Ocean.

\section{MATERIALS AND METHODS}

Sample collection and DNA extraction. South Africa's coral communities represent a small subset of reefs $(\sim 140 \mathrm{~km})$ that lack most of the geomorphological traits typical of tropical reefs. They are afforded a very high level of protection in a system of MPAs that are conveniently grouped into reef complexes. Samples of Pocillopora verrucosa were collected from Kosi Bay $\left(26^{\circ} 55.60^{\prime} \mathrm{S}, 32^{\circ} 53.23^{\prime} \mathrm{E}_{i} \mathrm{n}=18\right)$ in the Northern Reef Complex, from Nine-mile Reef $\left(27^{\circ} 25.12^{\prime} \mathrm{S}\right.$, $\left.32^{\circ} 43.39^{\prime} \mathrm{E}_{;} \mathrm{n}=17\right)$, Five-mile Reef $\left(27^{\circ} 29.81^{\prime} \mathrm{S}\right.$, $\left.32^{\circ} 41.72^{\prime} \mathrm{E} ; \mathrm{n}=17\right)$, and Two-mile Reef $\left(27^{\circ} 31.18^{\prime} \mathrm{S}\right.$, $32^{\circ} 41.37^{\prime} \mathrm{E}_{;} \mathrm{n}=14$ ) in the Central Reef Complex, and from Red Sands Reef $\left(27^{\circ} 45.84^{\prime} \mathrm{S}, 32^{\circ} 37.94^{\prime} \mathrm{E}_{;} \mathrm{n}=18\right)$ and Leadsmans Shoal $\left(27^{\circ} 50.90^{\prime} \mathrm{S}, 32^{\circ} 36.64^{\prime} \mathrm{E} ; \mathrm{n}=15\right)$ in the Southern Reef Complex (Fig. 1). North of these areas, the southern coast of Mozambique continues north for $850 \mathrm{~km}$ from the South African border, and the distribution of coral reefs along this section of coast is patchy, with only approximately $1 \%$ of reefs protected at Inhaca Island and Bazaruto Island. Samples of $P$. verrucosa were collected from both Bazaruto Island $\left(21^{\circ} 48.33^{\prime} \mathrm{S}, 35^{\circ} 29.53^{\prime} \mathrm{E} ; \mathrm{n}=16\right)$ and Inhaca Island (Fig. 1), but unfortunately the Inhaca samples were destroyed in transit. At each site, tissue samples were collected by removing small fragments, and all sampled colonies were separated by at least $3 \mathrm{~m}$. Coral tissue was removed from each fragment using an airgun connected to a scuba-cylinder, and resuspended in $20 \%$ DMSO preservation buffer (Seutin et al. 1991) and kept at $-20^{\circ} \mathrm{C}$ until further processing. DNA was extracted using a Qiagen Plant Mini extraction kit following the manufacturer's instructions. Due to the level of access and permit restrictions of working in regional MPAs, sample sizes were smaller than originally planned.

Microsatellite analysis. Recent population genetic assessments of Acropora palmata (Baums et al. 2005), Pocillopora meandrina (Magalon et al. 2005), and Seri- 


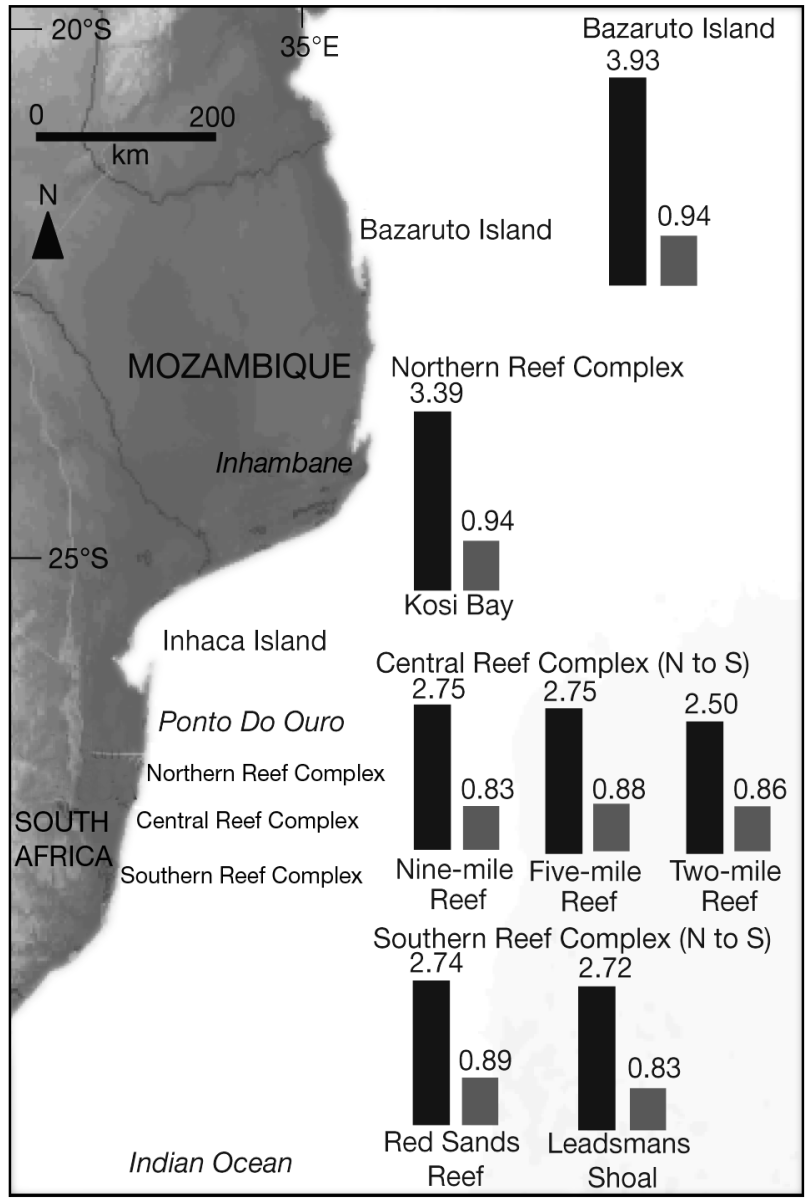

Fig. 1. Pocillopora verrucosa. Sampling locations within currently established Marine Protected Areas (MPAs) in southern Africa. South Africa: Kosi Bay in the Northern Reef Complex; Nine-mile Reef, Five-mile Reef, and Two-mile Reef in the Central Reef Complex; Red Sands Reef and Leadsmans Shoal in the Southern Reef Complex. Mozambique: Bazaruto Island. Unsampled reef locations are indicated in italics. Black bars: allelic richness; grey bars: genotypic diversity ratio $N_{\mathrm{g}}: N$ (see 'Genotypic structure'). Map outline courtesy of Reefbase (www.reefbase.org)

atopora hystrix (Underwood et al. 2007) provide support for the use of microsatellites as mainstream coral population markers, yet due to the technical issues with working with coral DNA (reviewed by Ridgway \& Gates 2006), when interpreting results it is important to highlight that the number of microsatellite loci available for corals is limited compared to other taxa. Four coral-specific microsatellites (PV7, PV6, PV5, PV2) were amplified for all samples of $P$. verrucosa as described by Magalon et al. (2004). The samples were genotyped on a GelScan 2000 (Corbett Research, Australia, modified from MacKenzie et al. 2004) using size standards (Promega, 25 to $350 \mathrm{bp}$ ). Known samples were run as references on all gels in order to ensure reliable scoring between gels. Data collection (25 to 35 min per run) was achieved using the software package GS2000 v 5.0 (Corbett Research), and the manual scoring of bands among gels was performed with Kodak 1D scan software alongside 4 size standard ladders.

Genetic diversity. General population genetic statistics and linkage disequilibrium were calculated and tested using GENEPOP (Raymond \& Rousset 1999). To adjust for uneven sample sizes, the number of alleles was inferred as allelic richness using FSTAT (Goudet 1995). The program DetSel (Vitalis et al. 2003) was used to detect signals of selection on any of the 4 loci by employing all possible pairwise comparisons for the 7 collection sites using 100000 coalescent simulations.

Genotypic structure. Departures of genotype frequencies from Hardy-Weinberg equilibrium (HWE) were expressed as Wright's fixation index $(f)$, and significant departures from the expected number of homozygotes and heterozygotes were calculated with chi-squared $\left(\chi^{2}\right)$ tests, using a sequential Bonferroni correction and calculated with GENEPOP (Raymond \& Rousset 1999). For all 7 sites, the multilocus genotype of each colony $(N)$ and the number of unique genotypes detected $\left(N_{\mathrm{g}}\right)$ were determined, with the ratio $N_{\mathrm{g}}: N$ providing the simplest index of the effects of asexual reproduction on genotypic diversity. However, because only a small portion of the genome can be sampled by the microsatellite loci, genotypically identical colonies may still be non-clonemates (Ayre et al. 1997), and the ratio $N_{\mathrm{g}}: N$ therefore provides the maximum estimate of the contribution of asexual reproduction to localised recruitment. The collection of colonies separated by at least $3 \mathrm{~m}$ would further reduce the chance of sampling genetic clones. Nevertheless, all statistical analyses were performed both on the original data and separately on a reduced data set with the exclusion of potential clones (as inferred from the $N_{\mathrm{g}}: N$ ratio)

Genetic differentiation. Pairwise $F$-statistics $\left(F_{\mathrm{ST}}\right.$, calculated as Weir \& Cockerham's $\theta$ ) based on the Infinite Alleles Model, and pairwise R-statistics $\left(R_{\mathrm{ST}}\right)$ based on the Stepwise Mutational Model were calculated using the program FSTAT (Goudet 1995) and significance determined when 0 lay outside the $95 \%$ confidence interval of the mean. The program GENALEX (Peakall \& Smouse 2001) was used to perform a Mantel test for isolation-by-distance.

$F_{\mathrm{ST}}$ analyses have been widely used in population genetic studies to date, yet the models of population structure, migration, and evolution on which they are based may not hold true in most cases (Whitlock \& McCauley 1999). Moreover, the identification of discrete population units is highly important in genetic assessments, especially when a species has a con- 
tinuous distribution, such as Pocillopora verrucosa in this study. Traditional estimators of population structure rely on the a priori designation of populations, meaning that their informative level will be reduced if the pre-defined populations are incorrect (Pearse \& Crandall 2004). However, newer methods overcome this problem by dividing the total sample up into clusters of individuals, each of which fits some genetic criteria that defines it as a group (Pearse \& Crandall 2004). STRUCTURE is a Bayesian clustering method that takes a sample of genotypes and uses the assumption of HWE and linkage equilibrium within subpopulations to find the number of populations (K) that best fit the data (Pritchard et al. 2000). Besides the work of Ridgway et al. (2001) showing that the Central and Southern Reef Complexes in South Africa were panmictic, there was no a priori information as to the likely number of $P$. verrucosa populations. Thus, as with Caribbean Acropora palmata populations (Baums et al. 2005), the number of genetically differentiated populations was estimated in the program STRUCTURE (Pritchard et al. 2000). The running parameters were: burn in $=100000$ iterations; 'admixture ancestry model'; 'correlated allele frequencies'; 5 simulations. $F_{\mathrm{ST}}$ were further calculated based on the clusters identified in the STRUCTURE analysis.

\section{RESULTS}

To test for effects of potential clones as inferred from the $N_{\mathrm{g}}: N$ ratio (see 'Genotypic structure'), all analyses were performed using the entire data set $(n=115)$ and the reduced data set wherein all potential clones were removed $(n=101)$. In all cases there was no significant difference in the results obtained (data not shown) and the data presented are based on the entire dataset.

\section{Genetic diversity and genotypic structure}

Among 42 linkage disequilibrium tests, none was significant $(p>0.05)$, indicating the genetic independence of all 4 loci. Samples of Pocillopora verrucosa were genetically diverse (Table 1), and genetic diversity decreased with increasing latitude. The allelic richness ranged from 3.93 to 2.50 (Fig. 1), with Bazaruto Island and Kosi Bay showing higher richness values than the reefs from the Central and Southern Reef Complexes. Bazaruto Island and Kosi Bay also contained private alleles not evident in the collections farther south (Table 1). Similarly, levels of expected and observed heterozygosity also decreased with increasing latitude (Table 1).
Genotypic frequencies for all loci differed significantly from expectations for $\operatorname{HWE}\left(\chi^{2}, \mathrm{p}<0.05\right)$, all primarily due to a deficit of heterozygotes (24 significant comparisons out of 28 after sequential Bonferroni correction). These departures were not consistent with the predicted effects of asexual reproduction, as asexual reproduction should produce both deficits and excesses of heterozygotes, whereas only heterozygote deficits were recorded. The DetSel analysis revealed that all loci fell within the $95 \%$ probability region in all pairwise comparisons, indicating no evidence for selection on the 4 loci. The examination of multilocus genotype frequencies also revealed little evidence of localised asexual reproduction (Fig. 1). Within every site, the majority of colonies displayed unique multilocus genotypes (i.e. $N_{\mathrm{g}}: N$ ranged from 0.83 to 0.94 ), and no genotype was represented by more than 2 colonies.

\section{Genetic differentiation}

Pairwise $F_{\mathrm{ST}}$ and $R_{\mathrm{ST}}$ analyses revealed very little significant variation among the South African reefs but higher values when compared to Bazaruto Island in Mozambique. Both $F_{\mathrm{ST}}$ and $R_{\mathrm{ST}}$ analyses showed identical patterns, with only 3 significant comparisons between Bazaruto Island and Five-mile Reef, Two-mile Reef, and Leadsmans Shoal $(\mathrm{p}<0.05$; Table 2 - only $F_{\text {ST }}$ shown for ease of presentation and to compare to other studies). $F_{\mathrm{ST}}$ values were within the range of reported studies on other broadcast spawning coral species. A Mantel test showed no evidence of isolationby-distance in the sampled reefs ( $p>0.05)$.

The Bayesian modelling approach of STRUCTURE identified 2 distinct population clusters as the most plausible scenario (log likelihood: $K=2$ is -1198) when no prior geographic information was presented (Fig. 2). Six of the 7 sampling localities were unambiguously assigned to 1 of the 2 clusters, thus greatly increasing the population sample sizes and therefore overcoming the potential limitation of the limited collections. The sampling localities were identified as belonging to Bazaruto Island in the north, and the Central and Southern Reef Complexes in the south, with Kosi Bay having mixed ancestry. Further subdivision of the data into more clusters was not supported (log likelihood: $K=1$ is $-1230 ; K=3$ is -1469).

To further explore the status of Kosi Bay, we re-ran the $F_{\mathrm{ST}}$ analysis by assigning Kosi Bay in turn to Mozambique in the north or to South Africa in the south. Although there was no significant differentiation based on $F_{\mathrm{ST}}$ when Kosi Bay was assigned with Bazaruto Island in the north $\left(F_{\mathrm{ST}}=0.022\right.$; Table 2$)$, the 
Table 1. Pocillopora verrucosa. Allele frequencies and observed $\left(H_{\mathrm{o}}\right)$ and expected $\left(H_{\mathrm{e}}\right)$ heterozygosity for populations within currently established Marine Protected Areas (MPAs) in southern Africa. Populations labelled from north to south (see Fig. 1). NRC: Northern Reef Complex; CRC: Central Reef Complex; SRC: Southern Reef Complex; (N): sample size. PV7, PV6, PV5, PV2: microsatellite loci; A-D: alleles

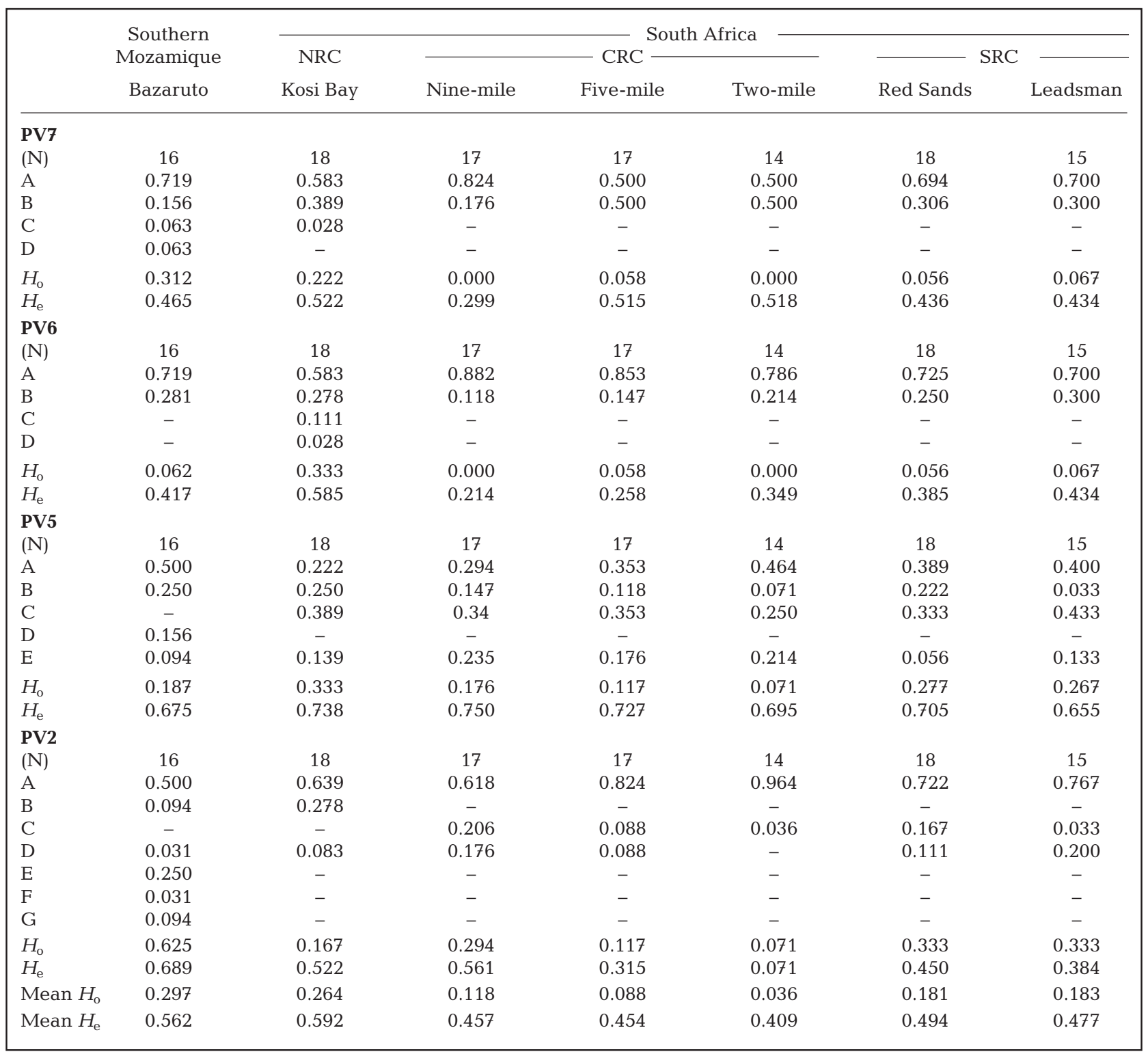

$F_{\text {ST }}$ value was significant $(p<0.05)$ when Kosi Bay was assigned with the other South African reefs in the south $\left(F_{\mathrm{ST}}=0.054 ;\right.$ Table 2$)$.

\section{DISCUSSION}

We used microsatellites to address the population structure of Pocillopora verrucosa as an initial estimate of connectivity among currently established MPAs in South Africa and Mozambique. Genetic differentiation was observed, suggesting weak connectivity between southern Mozambique and South African reef communities over ecological time scales, coupled with a genetic diversity gradient from north to south.

Genotypic frequencies for all loci differed significantly from expectations for $\operatorname{HWE}\left(\chi^{2}, \mathrm{p}<0.05\right)$, all due primarily to a deficit of heterozygotes. This result mirrors that recorded for Pocillopora verrucosa from the Central and Southern Reef Complexes based on allozymes (Ridgway et al. 2001) and is consistent with other microsatellite studies on corals, which all show significant deviations from HWE due to similar heterozygote deficits (Baums et al. 2005, Magalon et al. 
Table 2. Pocillopora verrucosa. Pairwise multilocus estimates of $F_{\mathrm{ST}}$ between populations within currently established Marine Protected Areas (MPAs) in southern Africa and between STRUCTURE clusters. Populations labelled from north to south (see Fig. 1). NRC: Northern Reef Complex, CRC: Central Reef Complex, SRC: Southern Reef Complex. Numbers in bold: $p<0.05$

\begin{tabular}{|c|c|c|c|c|c|c|c|}
\hline & \multirow{3}{*}{$\begin{array}{c}\text { Southern } \\
\text { Mozamique } \\
\text { Bazaruto }\end{array}$} & \multirow{3}{*}{$\begin{array}{c}\text { NRC } \\
\text { Kosi Bay }\end{array}$} & \multirow{2}{*}{\multicolumn{3}{|c|}{ South Africa }} & \multirow{2}{*}{\multicolumn{2}{|c|}{$\longrightarrow$ SRC $\longrightarrow$}} \\
\hline & & & \multirow[b]{2}{*}{ Nine-mile } & & & & \\
\hline & & & & $\begin{array}{l}\text { - CRC - } \\
\text { Five-mile }\end{array}$ & Two-mile & Red Sands & Leadsman \\
\hline Bazaruto & - & & & & & & \\
\hline Kosi Bay & 0.056 & - & & & & & \\
\hline Nine-mile & 0.053 & 0.042 & - & & & & \\
\hline Five-mile & 0.088 & 0.017 & 0.023 & - & & & \\
\hline Two-mile & 0.089 & 0.037 & 0.062 & -0.044 & _- & & \\
\hline Red sands & 0.034 & 0.004 & -0.015 & -0.013 & -0.011 & - & \\
\hline Leadsmans & 0.060 & 0.006 & -0.002 & 0.005 & -0.001 & -0.030 & - \\
\hline
\end{tabular}

2005, Maier et al. 2005, Underwood et al. 2007). Heterozygote deficits are a common feature of many marine populations (Ayre \& Hughes 2000), yet the exact mechanism driving this effect cannot always be determined. However, the consistently large deficits detected here seem most likely to be a consequence of inbreeding mediated either by self-fertilisation or restricted dispersal of gametes or larvae within $P$. verrucosa populations along the coast of southern Africa. Alternatively, the heterozygote deficits could be due to a Wahlund effect, where populations are admixed temporally or spatially, with the supply of recruits coming from genetically differentiated sources, suggesting that larval dispersal may be quite local. Whatever the exact cause, it appears that larval dispersal is somewhat local, which is consistent with the levels of genetic differentiation observed.

Genetic diversity decreases strongly with increasing latitude along the southeast African coast, with Bazaruto Island and Kosi Bay showing higher allelic richness values than the reefs from the Central and Southern Reef Complexes. The levels of expected and observed heterozygosity also decreased with increasing latitude, and this latitudinal effect was further reinforced in the examination of multilocus genotype frequencies. The data show that localised asexual recruitment had little influence on the maintenance of the collections studied; rather, they were maintained by sexual generation of larvae. All sampled locations were genotypically diverse, and on average, unique 4-locus genotypes could be assigned to $88 \%$ of all colonies (i.e. mean $N_{\mathrm{g}}: N=0.88$ ). Thus, it is clearly evident that populations of Pocillopora verrucosa in southeast Africa are sexual and that genetic diversity on the East African coastline decreases strongly with latitude. This latitudinal diversity gradient is interesting in that Ayre \& Hughes (2000) found no such gradient along $1000 \mathrm{~km}$ on the Great Barrier Reef (GBR) for 9 species of coral, yet a significant reduction in allelic diversity was evident when the same GBR populations were compared to the regionally isolated populations of Lord Howe Island (Ayre \& Hughes 2004). This trend is also found in the mangrove species Avicennia marina, where diversity decreases toward the edge of the distributional range (Arnaud-Haond et al. 2006). Given the location of the South African reef complexes at the southwestern extremity of the Indo-Pacific reef fauna and the southernmost extremes of coral communities on the African coastline, the reduced genetic diversity is likely to lower their potential resiliency to environmental change in much the same way as the high latitude communities at Lord Howe Island (Ayre \& Hughes 2004)

The extent of interconnectedness of coral reef organisms has come under scrutiny in the past decade, with Roberts (1997) proposing a high correlation between ocean currents and larval dispersal, and Cowen et al. (2000) suggesting that high diffusion and mortality of larvae results in local retention of larvae. In scleractinian corals, most genetic studies (e.g. Ayre \& Hughes 2000, Baums et al. 2005, Magalon et al. 2005) have indicated limited genetic differentiation over larger scales given sufficient stepping-stone reefs; however, subdivision occurs on the smaller within-reef scales. The mean $F_{\mathrm{ST}}$ values were 0.021 , which is higher than that previously recorded by allozymes in Pocillopora verrucosa from the Central and Southern Reef Complexes (Ridgway et al. 2001), and further support evidence from microsatellite studies of other broadcast spawning corals. For example, Magalon et al. (2005) reported mean $F_{\mathrm{ST}}$ values of 0.055 for $P$. meandrina in the South Pacific, and Baums et al. (2005) reported mean $F_{\mathrm{ST}}$ values of 0.036 across the Caribbean for Acropora palmata. In contrast, it appears that the dispersal potential of brooders (e.g. Maier et al. 2005, Underwood et al. 2007) is somewhat more limited than that of broadcast spawners (such as P. verrucosa). Despite the lack of significant geographic differentia- 


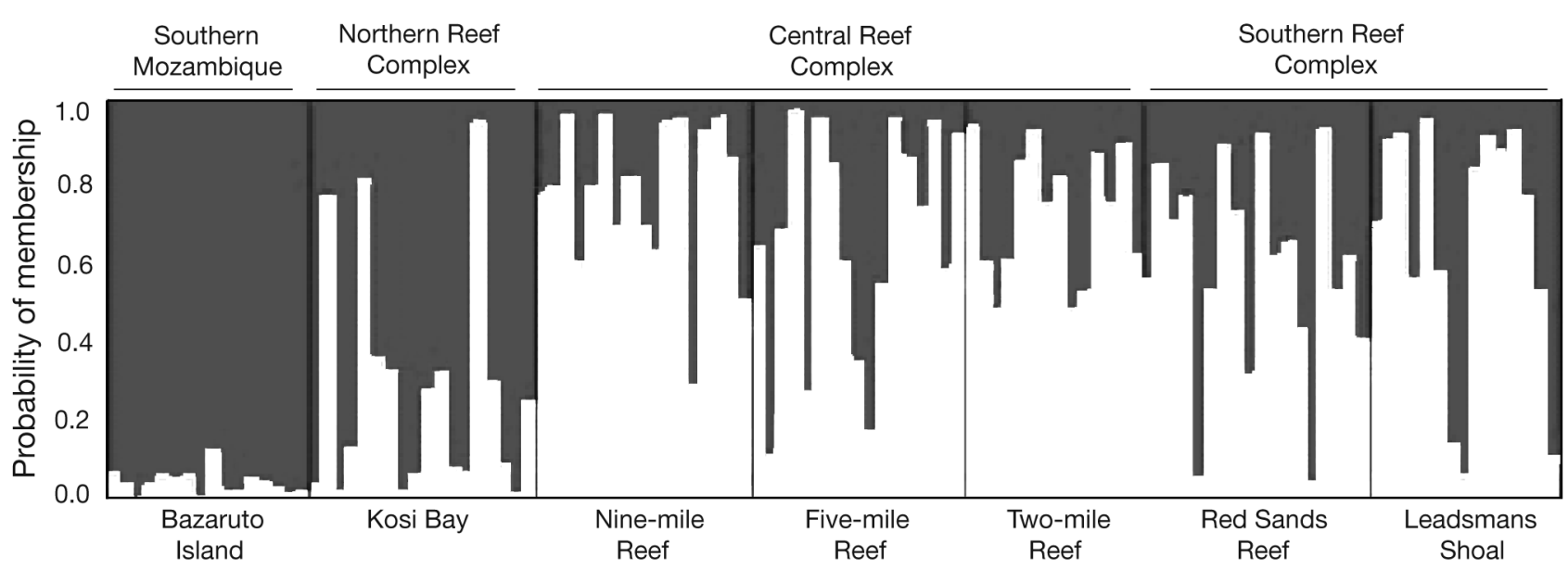

Fig. 2. Pocillopora verrucosa. Geographical subdivision of populations within currently established Marine Protected Areas (MPAs) in southern Africa as inferred using STRUCTURE ( $K=2$; no information provided about the geographical origin of the samples)

tion based on pairwise $F_{\mathrm{ST}}, 2$ distinct population clusters $(K=2)$ were identified as the most plausible scenario by STRUCTURE, when no prior geographic information was presented. Using these new clusters resulted in detection of significant levels of differentiation between Bazaruto Island and the South African reefs $\left(F_{\mathrm{ST}}=0.054\right)$, revealing noticeable genetic differentiation between southern Mozambique and South Africa.

While there is evidence of limited gene flow over ecological scales between Bazaruto Island and the South African reefs (separated by up to $600 \mathrm{~km}$ ), not all potential source reefs in southern Mozambique were sampled; coral reef communities exist at Inhambane, Inhaca Island, and Ponto Do Ouro (see Fig. 1 for locations). Unfortunately, due to site accessibility it was not possible to sample Pocillopora verrucosa from Inhambane and Ponto Do Ouro, and the collection from Inhaca Island was destroyed in transit. Nevertheless, reproductive studies that show $P$. verrucosa to be a synchronous broadcast spawner at new moon in midJanuary in southern Africa (Kruger \& Schleyer 1998) provide valuable insight into the results obtained regardless of the unsampled reefs. Broadcast spawning corals generally release gametes directly into the water column, and the larvae take several days to develop and settle (Harrison \& Wallace 1990); these characteristics allow them to disperse widely from the natal reef by wind-driven or ocean currents. However, Miller \& Mundy (2003) argued that the short competency periods and rapid settlement preferences of Platygyra daedalea and Goniastrea favulus suggest that dispersal in broadcast-spawning coral larvae may not be as great as previously assumed. The most important large-scale oceanographic feature in southeast Africa is the Agulhas current, which, due to a narrow continental shelf, flows close inshore in a southerly direction at approximately $1.5 \mathrm{~m} \mathrm{~s}^{-1}$ (Ramsay 1994). The results of our study therefore suggest that connectivity along the southern African coast most probably occurs over multiple generations through a stepping-stone array due to its linear nature and the strength of the Agulhas current. An isolation-bydistance pattern was not supported, but this may be a result of limited sample sizes and the intervening unsampled localities.

The design of marine reserve systems requires an understanding of larval transport in and out of reserves, whether reserves will be self-seeding, whether they will accumulate recruits from surrounding exploited areas, and whether reserve networks can exchange recruits (Palumbi 2003). While the subdivision within the 2 regional clusters is subtle and limited, the need to understand patterns of larval dispersal is particularly acute for the South African reefs because they are currently managed on the basis of the untested assumption that excluding human activities on the most northern and southern of the 3 reef complexes will provide sufficient protection. Within this management model, the northern reefs are expected to provide widely dispersed larvae to maintain the diversity of the Central and Southern Reef Complexes. Although the Northern Reef Complex appears to be an important larval source, despite the limited connectivity between Bazaruto Island and the South African reef complexes, the longterm survival of the South African populations likely depends on the transport of larvae southward, given the prevailing current. The reefs of southern Mozambique may therefore serve as additional sources of genetic variants, contributing recruits to the South African reefs over many generations via a stepping-stone approach, and if the upstream stepping-stones are lost, then the multi-generational connectivity over evolutionary time will also be broken up. This situation high- 
lights the complexity of marine conservation in that marine populations are not restricted to geographical boundaries, with upstream sources having the potential to affect the downstream populations, which in this case is a separate governmental entity.

Thus, despite the current level of protection of South African coral reefs, the lack of protection of potential upstream sources in southern Mozambique provides limited insurance for the downstream MPAs. MPAs work well as a conservation tool for networks of locations that are close together relative to the dispersal distance of larvae (Palumbi 2003); however, if there is insufficient protection, localised MPAs may only afford protection from localised threats such as overfishing, but they will provide little insurance against losses caused by larger scale disturbances such as coral bleaching.

Acknowledgements. This project was funded by a Winifred Violet Scott Award to T.R. and an Australian Research Council grant to O.H.-G.

\section{LITERATURE CITED}

Arnaud-Haond S, Teixeira S, Massa SI, Billot C, Saenger P, Coupland G, Duarte CM, Serrao A (2006) Genetic structure at range edge: low diversity and high inbreeding in Southeast Asian mangrove (Avicennia marina) populations. Mol Ecol 15:3515-3525

Ayre DJ, Hughes TP (2000) Genotypic diversity and gene flow in brooding and spawning corals along the Great Barrier Reef, Australia. Evolution 54:1590-1605

Ayre DJ, Hughes TP (2004) Climate change, genotypic diversity and gene flow in reef-building corals. Ecol Lett 7:273-278

Ayre DJ, Hughes TP, Standish RJ (1997) Genetic differentiation, reproductive mode, and gene flow in the brooding coral Pocillopora damicornis along the Great Barrier Reef, Australia. Mar Ecol Prog Ser 159:175-187

Baums IB, Miller MW, Hellberg ME (2005) Regionally isolated populations of an imperilled Caribbean coral, Acropora palmata. Mol Ecol 14:1377-1390

Berg H, Francis J, Souter P (2002) Support to marine research for sustainable management of marine and coastal resources in the Western Indian Ocean. Ambio 31:597-601

Cowen RK, Lwiza KMM, Sponaugle S, Paris CB, Olson DB (2000) Connectivity of marine populations: open or closed? Science 287:857-859

Goudet J (1995) FSTAT (version 1.2): A computer program to calculate F-statistics. J Hered 86:485-486

Harrison PL, Wallace CC (1990) Reproduction, dispersal and recruitment of scleractinian corals. In: Dubinsky Z (ed) Ecosystems of the world 25: coral reefs. Elsevier, New York, p 133-207

Kruger A, Schleyer MH (1998) Sexual reproduction in the coral Pocillopora verrucosa (Cnidaria: Scleractinia) in KwaZulu-Natal, South Africa. Mar Biol 132:703-710

MacKenzie JB, Munday PL, Willis BL, Miller DJ, van Oppen MJH (2004) Unexpected patterns of genetic structuring among locations but not colour morphs in Acropora nasuta (Cnidaria; Scleractinia). Mol Ecol 13:9-20
Magalon H, Samadi S, Richard M, Adjeroud M, Veuille M (2004) Development of coral and zooxanthella-specific microsatellites in three species of Pocillopora (Cnidaria, Scleractinia) from French Polynesia. Mol Ecol Notes 4: 206-208

Magalon H, Adjeroud M, Veuille M (2005) Patterns of genetic variation do not correlate with geographical distance in the reef-building coral Pocillopora meandrina in the South Pacific. Mol Ecol 14:1861-1868

Maier E, Tollrian R, Rinkevich B, Nürnberger B (2005) Isolation by distance in the scleractinian coral Seriatopora hystrix from the Red Sea. Mar Biol 147:1109-1120

McClanahan TR (1999) Is there a future for coral reef parks in poor tropical countries? Coral Reefs 18:321-325

Miller K, Mundy C (2003) Rapid settlement in broadcast spawning corals: implications for larval dispersal. Coral Reefs 22:99-106

Mora C, Sale PF (2002) Are populations of reef fish open or closed? Trends Ecol Evol 17:422-428

Palumbi SR (2003) Population genetics, demographic connectivity, and the design of marine reserves. Ecol Appl 13:S146-S158

Peakall R, Smouse PE (2001) GenAlEx V5: Genetic Analysis in Excel. Population genetic software for teaching and research. Australian National University, Canberra, Australia. Available at: www.anu.edu.au/BoZo/GenAlEx/

Pearse DE, Crandall KA (2004) Beyond $\mathrm{F}_{\mathrm{ST}}$ : analysis of population genetic data for conservation. Conserv Genet 5: 585-602

Pritchard JK, Stephens M, Donnelly P (2000) Inference of population structure using multilocus genotype data. Genetics 155:945-959

Ramsay PJ (1994) Marine geology of the Sodwana Bay shelf, southeast Africa. Mar Geol 120:225-247

Raymond M, Rousset F (1999) GENEPOP Version 3.1d. Available at: http://genepop.curtin.edu.au/

Ridgway T, Gates RD (2006) Why are there so few genetic markers available for coral population analyses? Symbiosis $41: 1-7$

Ridgway T, Sampayo EM (2005) Population genetic status of the Western Indian Ocean: What do we know? West Indian Ocean J Mar Sci 4:1-11

Ridgway T, Hoegh-Guldberg O, Ayre DJ (2001) Panmixia in Pocillopora verrucosa from South Africa. Mar Biol 139: 175-181

Roberts CM (1997) Connectivity and management of Caribbean coral reefs. Science 278:1454-1457

Roughgarden J, Armsworth PR (2001) Ecological economic theory for managing ecosystem services. In: Press $\mathrm{MC}$, Huntly NJ, Levin S (eds) Ecology: achievement and challenge. Blackwell Science, Oxford, p 337-356

Seutin G, White BN, Boag PT (1991) Preservation of avian blood and tissue samples for DNA analyses. Can J Zool 69: 82-90

Sheppard CRC (2003) Predicted recurrences of mass coral mortality in the Indian Ocean. Nature 425:294-297

Underwood JN, Smith LD, van Oppen MJH, Gilmour JP (2007) Multiple scales of genetic connectivity in a brooding coral on isolated reefs following catastrophic bleaching. Mol Ecol 16:771-784

Vitalis R, Dawson K, Boursot P, Belkhir K (2003) DetSel 1.0: computer program to detect markers responding to selection. J Hered 94:429-431

Whitlock M, McCauley DE (1999) Indirect estimation of gene flow and migration: $\mathrm{F}_{\mathrm{ST}} \neq 1 /\left(4 \mathrm{~N}_{\mathrm{m}}+1\right)$. Heredity 82 : $117-125$ 